EJIM

24,4

1110

Received 5 April 2020 Revised 16 May 2020 Accepted 28 May 2020

\section{Navigating the tensions in environmental innovation: a paradox perspective}

\author{
Nadia Di Paola and Tiziana Russo Spena \\ Department of Economics, Management, Institutions, \\ University of Naples Federico II, Naples, Italy
}

\begin{abstract}
Purpose - This study aims to investigate the hybrid nature and scope of environmental innovation (EI) by assuming a paradox perspective and developing it empirically. Specifically, the authors raise the questions of how the opposite elements of EI characteristics can be arranged and combined to generate benefits for companies and markets.

Design/methodology/approach - A fuzzy-set qualitative comparative analysis (fsQCA) is conducted to analyse European companies operating in telecommunications and in information and communication technology (ICT). This method helps us interpret the complexity occurring in the real world, in which the contribution of a specific attribute to the outcome might change according to other interacting and concurring aspects.

Findings - By recognising the conflicting aspects inherent to the complexity of EI, this study addresses how these tensions can be embraced. Specifically, the paradox logic is proposed to open EI strategy to a "both-and" perspective, with the purpose of making EI goals concretely feasible and integrated into a holistic view.

Practical implications - Paradoxical resolution denotes purposeful iterations between alternatives to ensure simultaneous attention to them over time. A paradox logic can support managers in making the EI strategy more workable and reconciling the extremes as well as possible.

Originality/value - This study unpacks the multiple enactments of EI by exploring the factors enabling integrated EI benefits. By adopting a paradox approach, the EI strategy may be interpreted in a "both-and" perspective, allowing firms to concretely achieve integrated EI benefits.
\end{abstract}

Keywords Environmental innovation, Fuzzy-set qualitative comparative analysis, Paradox approach Paper type Research paper

\section{Introduction}

Environmental topics are increasingly capturing the interest of different disciplines, i.e. economics, engineering and management, in the pursuit of solutions that address the core elements of the sustainability agenda in many industries (Blättel-Mink, 1998; Babiak and Trendafilova, 2011; Dangelico and Pujari, 2010; Ketata et al., 2015). According to the OECD Environmental Outlook, without further policies, global emissions of gases are projected to increase $37 \%$ by 2030 and $52 \%$ by 2050 , resulting in a $1.7-2.4^{\circ}$ increase in global temperature relative to pre-industrial levels. The need to tackle the consequences of climate change, including resource scarcity, the health impacts of pollution and biodiversity loss, cannot be denied by companies, which must address these challenges affordably and cost-effectively (Chang, 2011). In this context, environmental innovation (EI), i.e. innovation that reduces the environmental impact of production and consumption activities (Kiefer et al., 2017, 2019), is an integral aspect of strategy related to firm competition (Wagner, 2009; Khosravi et al., 2019).

(C) Nadia Di Paola and Tiziana Russo Spena. Published by Emerald Publishing Limited. This article is published under the Creative Commons Attribution (CC BY 4.0) licence. Anyone may reproduce, distribute, translate and create derivative works of this article (for both commercial and non-commercial purposes), subject to full attribution to the original publication and authors. The full terms of this licence may be seen at http://creativecommons.org/licences/by/4.0/legalcode

This paper is based on data from Eurostat, CIS survey, year 2014.
European Journal of Innovation Management Vol. 24 No. 4,2021 pp. $1110-1129$ Emerald Publishing Limited 1460-1060

DOI 10.1108/EJIM-04-2020-0111 
A considerable body of literature addresses the conflicting aspects of EI by discussing its opportunity and threat dichotomy (Babiak and Trendafilova, 2011; Kennedy et al., 2017). Firms' internal economic and cost-tied search for benefits has often dominated the explanation of why firms embrace EI (Schiederig et al., 2012; De Medeiros et al., 2014). Traditional studies have also indicated that economic factors could contrast with a broader strategic approach; some companies are unlikely to adopt EI because it can stray too far from their knowledge or because EI is high risk (Lee et al., 2006; Marin and Lotti, 2017).

More recent approaches have started to address EI objectives as more inextricably connected to strategic and market goals (Bonzanini-Bossle et al., 2016). In this sense, EI has been seen as an important strategic asset for firms to successfully compete and satisfy new market needs while generating long-term benefits (Adams et al., 2016). EI issues are complex, spanning across different knowledge domains (Chen et al., 2012) and are systemic in nature (Dangelico, 2016). EI can require a radical technological change or even the change of a whole system; it can span a rich spectrum, from processes to products and markets (Horbach et al., 2012; Gilli et al., 2014) and combine firm benefits with benefits for other actors (Klewitz and Hansen, 2014; Kiefer et al., 2019).

Moreover, the focus on the complex approach to EI has recently recognised the role of collaboration with external partners to better address companies' strategic and integrated EI objectives (Ketata et al., 2015; Ghisetti et al., 2015; Hu et al., 2017; Mothe et al., 2017; Stadtler and Lin, 2019).

Notwithstanding the richness of contributions in illuminating the different and complex attributes of EI, a great part of the debate still hinges on the traditional dichotomies of innovation. Many aspects are discussed in conflicting terms. Radical and incremental (Del Río et al., 2017; Rave et al., 2011), product and process (Belin et al., 2011; Doran and Ryan, 2016), market and technological (Carrillo-Hermosilla et al., 2010) and institutional and strategicdriven practices (Leyva-de la Hiz et al., 2019; Rexhäuser and Rammer, 2014) are some differences that are still assumed. The relationships between these aspects are fraught with tensions, and scholars and practitioners most commonly conceptualise the interplay among them as contradictions that are difficult to manage.

Although scholars have recently assumed the coexistence of more EI objectives and benefits, studies generally distinguish among different EI-enabling factors by assuming an either-or logic. This approach misses the opportunity to truly understand the complex and hybrid nature of the EI phenomenon.

Recently, the paradox approach has been advanced as an emergent perspective by studies on sustainability (Hahn et al., 2014, 2018; Lewis and Smith, 2014; Schad et al., 2016) to overcome the traditional vision based on contradictions. It recognises the possibility that opposing elements (for example, social, economic and business) can be seen as complementary and managed accordingly. However, most of these studies are conceptual in nature, few present empirical analyses and none specifically concerns EI.

Addressing this gap in the literature, our study aims to investigate the hybrid nature and scope of EI by assuming a paradox perspective and developing it empirically. The following research question is posed: How do firms manage tensions in each one of the EI components to achieve integrated EI benefits?

Based on literature we identified three main dimensions of EI, i.e. types of EI, forces leading to EI and modes of EI, which are included for consideration in our paradoxical frame. We investigate the influence of combining either-or aspects of each single dimension of EI on the attainment of complex EI benefits.

A fuzzy-set qualitative comparative analysis (fsQCA) based on Boolean algebra is conducted to analyse European companies operating in telecommunications and in information and communication technology (ICT). We use data from the 2014 Community Innovation Survey (CIS). We focus on telecommunications and ICT companies due to the high
The hybrid nature and scope of EI 
EJIM

24,4

1112

pace of innovation in the industry and its environmental impact, which poses serious strategic challenges to the EI approach of firms (Rashidirad et al., 2018).

This study unpacks the multiple enactments of EI by exploring the factors enabling integrated EI benefits. By recognising the conflicting aspects inherent to the complexity of EI, this study addresses how these tensions can be embraced. Specifically, the paradox logic is proposed to open EI strategy to a "both-and" perspective, with the purpose of making EI goals concretely feasible and integrated in a holistic view.

The rest of this paper is organised as follows. First, we analyse the EI literature, specifically focussing on the dichotomies and conflicting aspects of EI. Then, we present the theoretical paradox framework and condition to address the multifaceted nature of EI. The methodological section presents the empirical research design, and the findings provide evidence of the relevant EI dimensions and their enabling factors. The conclusions and implications close the paper.

\section{Environmental innovation: dichotomies and conflicting aspects}

Identifying and characterising the dichotomies and tensions in EI has generated an extensive debate in the literature (Baumgartner, 2011; Díaz-García et al., 2015). EI is far from a monolithic concept (Franceschini and Pansera, 2015; Hojnik and Ruzzier, 2016), and there is some argument about the expression and understanding of the term "environmental innovation". The term covers a range of definitions and terminologies, such as green innovation (Chang, 2011; Chen et al., 2012), eco-innovation (Hellstrom, 2007; Halila; Rundquist, 2011; Bonzanini-Bossle et al., 2016) and sustainability-driven innovation (Hall et al., 2018); the former two terms are usually seen as synonymous, while the last is used to extend the concept to the social impact of innovation.

Through comprehensive comparisons of different concepts, the literature has proposed different logics. Through the internal logic, the economic dimension is prioritised over external or market aspects (Hellstrom, 2007), and more recently, the integrative logic considers all aspects of EI (Klewitz and Hansen, 2014; Hall et al., 2018). In this contraposition, less innovative firms are demonstrated to adopt EI as a mean to reduce production costs and comply with the minimum environmental standards, while more innovative firms adopt eco-innovation with a greater strategic intent (Horbach et al., 2012; Huber, 2008).

EI issues are typically complex (Dangelico, 2016). This complexity is often related to the higher level of technology required to develop EI, but it also results from the uncertainty and variety of market issues that companies need to address to innovate environmentally (Gilli et al., 2014; De Marchi, 2012). The characteristics and dimensions of different EI types have been identified (Doran and Ryan, 2016; Kiefer et al., 2017), shaping diversity in the underlying processes and outcomes of EI. As EI is an ambiguous phenomenon, the limited consensus about what EI means focuses on the multiple aspects of EI's nature and practices and their links with its substantive benefits.

Some scholars have noted that EI introduces ecological ideas into the development of new products, markets and systems or even economic strategies (Aschehoug et al., 2012; BlättelMink, 1998; Horbach, et al., 2012); others have proposed that EI consists of a series of applications in newly developed or improved processes related to technologies, practices, systems and products to avoid or reduce environmental hazards (Gonzalez-Padron and Nason, 2009; Gilli et al., 2014). EI is also defined as concerning the exploration, assimilation or development of a product, process and/or service (Cleff and Rennings, 1999) or as a novel management method reducing environmental risks, pollution and other adverse effects on resource utilisation (Huber, 2008, Carrillo-Hermosilla et al., 2010). Additionally, EI can include considerations of the whole life cycle of products (Huber, 2008) or a specific firm's internal processes (del Rio et al., 2016). Scholars have also indicated that EI is a general term for a series of innovative activities that help improve the quality of the ecological environment and 
contribute to sustainable development (Hellstrom, 2007; Pujari, 2006). However, while product innovation has been considered the logical complement of process innovation for EI (Xie et al., 2019), it has nevertheless been demonstrated that some companies are unlikely to adopt both because they can stray too far from their knowledge or because they fail due to the higher risk of such innovation (Livonen, 2017).

Moreover, scholars are still far from forming a consensus on the external and internal pressures driving EI. Studies distinguish EI with respect to voluntary versus compliance motivations (Berrone et al., 2013; Horbach et al., 2012; Porter and Van der Linde, 1995). Scholars who adopt the legitimacy approach argue that an environmental issue is strongly influenced by the external setting in which firms operate (Darnall et al., 2010; Hoogendoorn et al., 2015). The reactive frame is a typical pragmatic firm stance; it involves a propensity to pursue legitimacy responses by improving existing routines and processes and increase legitimacy. The focus is on reconciling the opposing sides of multi-stakeholder demands with firm goals of cost containment and overall efficiency improvement (Hojnik and Ruzzier, 2016). Investments in firm resources and a proactive approach are indeed encouraged to address the increasing turbulence of environment-driven competition (Aragón-Correa and Rubio-López, 2007; Hall et al., 2018) coupled with the opportunity to communicate the benefits of environmental attributes for more strategic goals (both internally and externally; Buysse and Verbeke, 2003). The proactive approach is widespread in the research on links between environmental strategy and firm performance (Albertini, 2013; Aguilera-Caracuel and Ortizde-Mandojana, 2013; Darnall et al., 2010; Hall et al., 2018). Scholars agree that firms need to contextually ensure their alignment with regulation and address issues of technology and demand (Camisón, 2010; Liao, 2018) as well as communicate with and engage different stakeholders and avoid the mechanism of knowledge lock-in (Murillo-Luna et al., 2011; Yang, et al., 2019). Studies have also demonstrated that the effects of the combinative nature of such pressures are not isomorphic, as in the case of strong institutional pressure, where companies follow different logics with different results in terms of the type of EI objectives (Chen et al., 2012; Testa et al., 2018).

Similarly, recent studies on open EI have assumed that different logics lead to the modes of collaboration for EI (Ghisetti et al., 2015). Collaboration enables firms to access differentiated knowledge and target the generation of more effective processes, solutions and products that contextually capture both internal objectives and market value options (Yin et al., 2018). External technological acquisition is associated with EI, especially at the internal and product stages (De Marchi and Grandinetti, 2013; Kennedy et al., 2017; Zhao et al., 2018). Upstream interactions with suppliers (i.e. environmental co-makerships) (Triguero et al., 2018; Yarahmadi and Higgins, 2012) and industrial network members (i.e. other economic actors that are connected to the company) are demonstrated to be crucial for solving technological issues in the eco-innovation process and for generating positive internal benefits (Halila and Rundquist, 2011; Cainelli et al., 2012; De Marchi, 2012). Additionally, the effectiveness of open innovation for firms could differ depending on whether firms are already ahead of their peers in eco-innovation investments and activities. A direct link between internal and external knowledge to which a company has access through collaboration with partners and the success of its EI processes has been demonstrated (Mothe and Nguyen-Thi, 2017; Rauter et al., 2017; Li-Ying et al., 2018).

Previous studies on attitudes towards or intentions to adopt EI often note a company's needs to navigate between multiple tensions that can constitute logical opposites and/or complements (see Table 1).

Scholars tend to conceptualise the EI dimensions in terms of contradictions and tensions and try to investigate how to solve them (Livonen, 2017). In contrast, we put forward the idea that conceptual arguments support the use of a paradox approach to explore ambiguous and multifaceted issues relating to EI in order to unveil EI's potential to generate complex and integrated benefits.
The hybrid nature and scope of EI 


\section{EJIM 24,4}

\section{4}

\begin{tabular}{|c|c|c|}
\hline & Either-or dilemma & Main reference \\
\hline $\begin{array}{l}\text { Types of } \\
\text { environmental } \\
\text { innovation }\end{array}$ & $\begin{array}{l}\text { Product-process } \\
\text { Market-R\&D driven } \\
\text { Organisational-strategic } \\
\text { changes } \\
\text { Quality improvement- } \\
\text { sustainable development }\end{array}$ & $\begin{array}{l}\text { Doran and Ryan (2016); Cleff and Rennings(1999); } \\
\text { del Rio et al. (2016); Carrillo-Hermosilla et al. (2010); } \\
\text { Gilli et al. (2014); Gonzalez-Padron and Nason (2009); } \\
\text { Hellstrom (2007); Horbach et al. (2012); Huber (2008), } \\
\text { Livonen (2017); Pujari (2006); Xie et al. (2019) }\end{array}$ \\
\hline $\begin{array}{l}\text { Forces of } \\
\text { environmental } \\
\text { innovation }\end{array}$ & $\begin{array}{l}\text { Business-regulatory } \\
\text { pressures } \\
\text { Legitimacy-strategic } \\
\text { approach } \\
\text { Proactive-reactive } \\
\text { approach }\end{array}$ & $\begin{array}{l}\text { Aragón-Correa and Rubio-López (2007); Berrone } \\
\text { et al. (2013); Chen } \text { et al. (2012); Buysse and Verbeke } \\
\text { (2003); Camisón (2010); Darnall et al. (2010); Hall et al. } \\
\text { (2018); Hojnik and Ruzzier (2016); Hoogendoorn et al. } \\
\text { (2015); Horbach et al. (2012); Liao (2018); Murillo- } \\
\text { Luna et al. (2011); Porter and Van der Linde (1995); } \\
\text { Testa et al. (2018); Yang, et al., } 2019\end{array}$ \\
\hline $\begin{array}{l}\text { Modes of } \\
\text { environmental } \\
\text { innovation }\end{array}$ & $\begin{array}{l}\text { Internal-external } \\
\text { knowledge focus } \\
\text { Close or loose } \\
\text { collaborations } \\
\text { Supply-networked } \\
\text { collaborations }\end{array}$ & $\begin{array}{l}\text { Cainelli et al. (2012); De Marchi and Grandinetti } \\
\text { (2013); De Marchi (2012); Ghisetti et al. (2015); Halila } \\
\text { and Rundquist (2011); Kennedy et al. (2017); Li-Ying } \\
\text { et al. (2018); Mothe and Nguyen-Thi (2017); Rauter } \\
\text { et al. (2017);Triguero et al. (2018), Yarahmadi and } \\
\text { Higgins (2012); Yin et al. (2018) }\end{array}$ \\
\hline
\end{tabular}

Table 1.

EI characteristics and tensions

\section{Theoretical framework: the paradox approach to EI}

Due to inherent tensions in EI (Dangelico, 2016), the complex nature of EI must be reconciled to support a more effective EI strategy.

Recently, the paradox theory has been advanced as a new perspective by studies on sustainability and corporate social responsibility (Hahn et al., 2014, 2018; Lewis and Smith, 2014; Ivory and Brooks, 2018; Soderstrom and Heinze, 2019). Rooted in classical Eastern and Western cultures (Schad et al., 2016), this meta-theoretical approach aims to overcome the traditional vision based on contradictions by recognising opposing elements as complementary ones. O'Driscoll states (2008, p. 96), exploring paradox, seeking to find a resolution of conflicting yet credible forces and searching for a synthesis, become an inclusive, multivocal and pluralistic process. The paradox approach presupposes that actors are most effective when they accept contradictory elements as simultaneously valid and handle them via a combination of separation and synergy, rather than attempting to silence the tension between them (Lewis and Smith, 2014).

Here, we use the paradox perspective to explore EI as a multidimensional and complex phenomenon in more detail and to highlight ways that different EI tensions can be accommodated and managed. Specifically, the paradox approach (Hall et al., 2018; Zeng et al., 2017) has been used to illuminate the integrated nature of EI objectives and to reason in terms of "synergistic and interwoven polarities" that characterise EI components. The previous literature section elaborates on the specific conflicting aspects of EI, which include three main elements. types of innovation, forces leading to innovation and modes of innovation (see Table 1). Building on this literature, we discuss in depth how companies can address the tensions in each one of the EI components for substantive EI responses.

Regarding types of innovation, studies indicate that performance improvement in the underlying processual and organisational aspects of EI is necessary for every product EI (Adams et al., 2016). Scholars have argued that some assumptions concerning different EI types can be complementary in the case of EI strategic environmental goals but not in the case of reasons for cost efficiency (Xie et al., 2019). Thus, the either-or paradox dilemma can be useful to account for the increasing complexity of EI typologies (Yang et al., 2019; Xie et al., 2019) in order to address their complementary or opposing forces. 
Concerning forces leading to EI, studies explicitly acknowledge the importance of regulative and normative pressures and the compliance motivations that they generate (Sánchez-Medina et al., 2015). In this regard, some studies have focused on companies that embrace innovation for a more eco-efficient optimisation of current processes in response to normative pressures (Carrillo-Hermosilla et al., 2010); other scholars have addressed the need for improved solutions for increasing their market and competitive forces (De Medeiros et al., 2014). Although evidence supports the notion that companies responding to normative pressures do not necessarily sacrifice their broader competitive and strategic goals (Testa, et al., 2018), studies explicitly accounting for their distinct or combinative influences are still missing. The paradox approach can better capture the opportunities of combining the positive effects of regulative pressures and firms' environmental strategic goals (Camisón, 2010; Porter and Van der Linde, 1995).

Finally, by taking a broad view of EI modes and the type of technologies or knowledge involved, the most recent studies stress the crucial role of external acquisition in enhancing the positive effects on EI performance (Ghisetti et al., 2015; Hu et al., 2017). These results point to the role of knowledge resources and dynamic capabilities as an important intrinsic driver of voluntary EI (Galbreath, 2019; Kesidou and Demirel, 2012). The focus is on both internal and external knowledge sources and on a firm's ability to create, extend and modify its resource basis to address changing business and environmental requirements (Bönte and Dienes, 2013). Here, the paradox perspective could be useful to address the need to accommodate the acquisition of external new technologies and open practices with internal knowledge resources and knowledge processes to address multiple EI benefits and reduce its risks and uncertainties (Bonzanini-Bossle et al., 2016).

Our framework relies on the tensions regarding each of EI components and elaborates on their extension to investigate whether they may be assumed to coexist or if their presence is rather than mutually exclusive (Schad et al., 2016). In line with the paradox perspective, the framework navigates the possibility of expanding and combining opposite elements of each EI components by assuming that one characteristic does not exclude the others. This illuminates how EI tensions can be temporarily resolved to achieve multiple benefits of EI strategy.

\section{Research process}

The relationship between the ways in which firms address tensions regarding the types of innovation, the forces leading to innovation, the modes of innovation and firms' substantive EI responses was analysed by using fsQCA, which is a set-theoretic method that is based on Boolean algebra (Ragin, 2008) and is increasingly adopted in managerial studies (Kraus et al., 2018; Di Paola and Russo-Spena, 2019). We choose this method for three reasons. First, this method allows us to reason in terms of equifinality because it considers that different conditions might lead to the same outcome. In other words, by using fsQCA, we can consider that in the real world, it is possible that different actions lead to the same result. Second, fsQCA admits conjunctural causation, i.e. the possibility that different aspects interact and contribute to generating an outcome. In this sense, the methodology helps us understand whether and how the different aspects may be addressed to manage a multidimensional phenomenon. Third, fsQCA helps us interpret the complexity occurring in the real world, in which the contribution of a specific attribute to the outcome might change according to other interacting and concurring aspects; this is called causal asymmetry (Schneider and Wagemann, 2012; Fiss, 2011).

We put forward the idea that through the fsQCA approach, it is possible to overcome the dichotomous perspective linked to the either-or dilemma and test the possibility that some apparently conflicting attributes of EI could actually coexist within the same company with regard to its responses to EI challenges.
The hybrid nature and scope of EI 
EJIM

24,4

1116

\subsection{Data collection}

We collected data from the 2014 CIS database. This database contains firm-level data related to innovation in all European companies included in the Statistical Classification of Economic Activities in the European Community (nomenclature statistique des activités économiques dans la Communauté européenne, NACE) Rev. 2, sections A to N. It is owned by Eurostat, which allowed the authors use of the database for a limited period.

Our analysis is focused on ICT companies included in NACE sections A and B and is specifically related to the following codes: 61, telecommunications; 62 and 63, telecommunication and ICT services; and 58-60, publishing, audio-visual and broadcasting activities. We focus on telecommunications and ICT companies for at least two reasons. First, these industries are constantly investing despite high risks, and the effects of risk-taking are debated from an environmental point of view (Holm and Østergaard, 2015). Aspects related to the intensive use of energy and rare materials, to the increasingly rapid planned obsolescence of products and to the management of e-waste merit attention (Heeks et al., 2015). Second, this industry is facing an increasing pressure on stakeholders to address environmental demands. As a consequence, companies compete for differentiation from an environmental point of view.

Based on data availability, our dataset includes the following ten countries: Bulgaria, Croatia, Cyprus, Estonia, Greece, Hungary, Latvia, Lithuania, Romania and Slovakia. A total of 6,690 firms in these countries were included in the survey. We then selected firms as follows. First, we selected firms according to their EI activity, choosing firms that had introduced at least one innovation that generated environmental benefits. As a result, the dataset included 558 companies. Then, we concentrated on companies that had implemented systematic reporting, practices and procedures relating to the generation of environmental benefits. The reports show evidence that these organisations were acting on recommendations to include more performance-based environmental goals and to embrace a more future-oriented approach. We chose to focus on companies that consciously and effectively implemented EI and monitored their effects. Finally, all data were reviewed for completeness, and the results of the data cleaning check produced a list of 102 investigated companies. Two-thirds of the companies are part of a group, and most of them sell abroad (see Table 2).

Our analysis aimed to understand whether and what relationships existed between the tensions relating to types of innovation, forces leading to innovation and modes of innovation and the substantive benefits relating to the EI responses of firms. According to the fsQCA terminology, we call the three different tensions the conditions and call the environmental benefits the outcome.

More specifically, each company was conceived as a combination of those conditions, and the value measured for each condition represented the degree of belonging or non-belonging of that specific company to the set identified by the condition (Kan et al., 2016). The fsQCA was sensitive to the presence or absence of each of the conditions in the sense that the

\begin{tabular}{ll}
\hline & N. of companies \\
\hline Corporate group & Included : N.69 \\
& Not included: N.33 \\
Number of employees & Less than 50: N.36 \\
& $50-249:$ N. 26 more than 250: N. 30 \\
Selling market & N.A: 10 \\
& Only Regional and national market: N.21 \\
& International market: N.81
\end{tabular}

Table 2.

Descriptive statistics of Selling market the dataset 
presence or absence of certain conditions could be found to be relevant for generating the outcome.

\subsection{Measures}

Below, we detail the constructs and the measures used.

4.2.1 Integrated EI benefits. The EI benefits (the outcome) included the different typologies of environmental benefits generated by a company. Different kinds of benefits were considered (Bonzanini- Bossle et al., 2016) and were categorised into two groups: (1) internal benefits within the firm (i.e. reduced material or water use; reduced internal energy use; reduced internal pollution; replaced materials; replacement fossil energy and recycled waste, water or materials) and (2) external benefits for the market (i.e. end-users: reduced general energy use; reduced general pollution; facilitated recycling; and extended product life cycle). Then, a unified measure was obtained by comparing the relative frequencies of each category of benefits. This measure is equal to 1 when the relative frequencies of the two categories of benefits (internal and external) are the same, i.e. the two categories are jointly present and to 0 when they are not.

4.2.2 Types of EI. This condition measures the presence of different types of EI. For this measure, two types of EI were considered: (1) product/market innovation and (2) process/ organisational innovation (Aschehoug et al., 2012; Cleff; Rennings, 1999). A unique measure was obtained by comparing the values of the two categories. Consequently, the condition is 0 when only one of the two categories of innovation is present (i.e. product/market innovation or process/organisational innovation), and the condition is 1 when both categories of innovations are introduced by the company.

4.2.3 Forces leading to EI. This condition measures the level of importance of different pressures leading to EI. For this measure, different forces were considered (Berrone et al., 2013) and categorised into (1) regulatory and public pressures (i.e. existing environmental regulations; existing environmental taxes and grants or incentives) and (2) business pressures (i.e. current market demand; enterprise reputation; voluntary actions for environmental good practices; high cost of energy, water and materials and need to meet requirements for public procurement contracts), respectively. For each force, the level of importance was scored on a scale from 0 (minimum level) to 3 (maximum level). Then, a unique measure was obtained by comparing the level of importance of the two categories. The condition is equal to 1 when the two categories are scored as important (levels equal to 2 or 3) and is equal to 0 when one or both categories of forces are not scored as important (levels equal to 0 or 1 ).

4.2.4 Modes of EI. This condition measures the coexistence between the different modes of innovation that might be related to EI. For this measure, different modes of innovation were considered (Ghisetti et al., 2015; Hu et al., 2017) and were categorised into (1) close innovation, i.e. innovation based on internal resources investment, (i.e. investment in in-house R\&D) and (2) collaborative innovation, i.e. based on external resources acquisitions, (i.e. external R\&D collaborations; acquisition of technology such as machinery, equipment and software; and acquisition of existing knowledge from other enterprises or organisations). Then, a unique measure was obtained by comparing the relative frequencies of each mode category. Consequently, the condition is equal to 1 , when the two categories of innovation modes are both present and to 0 when they are not.

\subsection{Calibration process}

To implement the fsQCA procedures, a preliminary step of analysis was to express all conditions and the outcome in a standardised manner. This resulted in the need to subject all original measurements to a calibration process (Schneider and Wagemann, 2012). For each
The hybrid nature and scope of EI 
EJIM

24,4

1118

case/company, the calibrated values of the conditions varied between 0 and 1 , and those values indicated the degree of belonging of each case to the set linked to the condition considered. More specifically, 0 was associated with a full non-membership situation, 1 with a full membership situation and 0.5 with the point of maximum ambiguity (or cross-over point).

We perform a direct calibration procedure and thus need three qualitative anchors. We obtained them by relying on the internal distribution of cases, searching for discontinuities (Table 3). We calculate the degree of membership by using the logistic function, which assumes the typical $S$-shape (Ragin, 2008; Dusa, 2019, Appendix 1).

For the full membership of each case in the conditions, the calibration values are 0.9 for types of EI and forces leading to EI and 0.833 for modes of EI. For the outcome, the qualitative anchor values are 0.375 (full non-membership), 0.625 (maximum ambiguity) and 0.875 (full membership).

\subsection{Data analysis}

We use specific software to carry on the analysis (Dusa, 2019). This analysis included several steps. First, we created a truth table, which was useful to visualise all the possible combinations of conditions and associate them to the cases. The total number of possible combinations with 3 conditions is $2^{\wedge} 3$, i.e. a fully populated truth table would have 8 rows (Cooper and Glaesser, 2016). After setting an appropriate definition of the frequency (i.e. the minimum number of cases in which the configuration is observed) and consistency thresholds (i.e. "how closely a perfect subset relation is approximate"; Ragin, 2008, p. 44), we proceeded to a process of logical reduction of the truth table. In our case, 1 and 0.9 were the frequency and consistency thresholds to test the necessity (Legewie, 2013), and 1 and 0.85 were the frequency and consistency thresholds of the sufficiency test. These thresholds are in line with those suggested by the extant literature (Ragin, 2000).

Then, after the logical reduction, we proceeded with the necessity and sufficiency tests. Those tests allowed us to identify the conditions that were most frequently associated with the emergence of the outcome and to understand whether they were necessary and/or sufficient for this emergence (Ragin, 2008). A necessary condition is defined as a condition without which an outcome never occurs, while a sufficient condition is the one that is able to generate an outcome; in other words, if the condition occurs, then the outcome occurs (Ragin, 2008).

We obtained the solution paths to the sufficiency test by applying the Quine-McCluskey algorithm and considering its parsimonious solution (Ragin, 2008). The traits of the fsQCA

\begin{tabular}{lll}
\hline Construct & Calibration rule & Membership score \\
\hline Benefits & If out $<0.375$ & 0 (full non-membership) \\
& If out $=0.625$ & 0.5 (cross-over point) \\
Types & If out $>0.875$ & 1 (full membership) \\
& If $<0.1$ & 0 (full non-membership) \\
Forces & If $=0.5$ & 0.5 (cross-over point) \\
& If $>0.9$ & 1 (full membership) \\
Modes & If $<0.1$ & 0 (full non-membership) \\
& If $=0.5$ & 0.5 (cross-over point) \\
& If $>0.9$ & 1 (full membership) \\
& If $<0.166$ & 0 (full non-membership) \\
& If $=0.5$ & 0.5 (cross-over point) \\
& If $>0.833$ & 1 (full membership)
\end{tabular}


supported us in identifying the typical cases, that is, the cases that verified the outcome and were associated with one (or more than one) of the solution paths.

\section{Findings}

The fsQCA allowed us to test the logical connections between the combinations of conditions and the outcome, which is the ability of a firm to generate integrated environmental benefits, i.e. both internal (for itself) and external (for the market). Those logical connections consist of information about necessary and sufficient conditions for an outcome to occur.

Our dataset is not affected by limited diversity, that is, it does not present logical remainders, since it contains at least one case for each one of the possible combinations of conditions (Schneider and Wagemann, 2012). Our first results show that none of the conditions analysed, i.e. types of EI, forces leading to EI, or modes of EI, is necessary to observe the outcome (see Table 4). More specifically, the consistency threshold for the detection of a necessary condition is set at 0.9 , but the three conditions, namely types of EI, forces leading to EI and modes of EI reach consistency parameters equal to $0.56,0.80$ and 0.84 , respectively. Thus, the results of the necessity test show that there is no situation in which any of the conditions must occur to achieve integrated EI benefits.

The results of the sufficiency test revealed three different paths as possible combinations of conditions leading firms to achieve integrated environmental benefits. In Table 5, each Boolean algebra expression indicates the combinations of conditions that are sufficient for generating our outcome. The three solutions obtained show a good consistency level, equal to 0.87 for path 1, 0.89 for path 2 and 0.94 for path 3 (Ragin, 2008).

These results were also confirmed by a robustness check (Skaaning, 2011). These three solution paths are associated with 21 companies in our dataset, i.e. the typical cases. In our study, all typical cases generate internal (benefits within the firm) and external (for the market and customers) environmental benefits at the same time because they express one of the combinations of conditions represented by the solution paths.

More specifically, the path 1 (including ten companies) shows that types of EI are the only condition that requires embracing its intrinsic tensions; i.e. both product and process innovation are needed for companies that want to achieve integrated EI benefits. However combined EI types produce integrated EI benefits when the different innovation modes are not jointly present. The solution path 2 indicates that the outcome is also reached when the different types of innovation are combined only with some kinds of forces. This path shows the same number of companies included in the previous path. As an additional result, solution path 3 (including 3 companies) indicates that integrated environmental benefits also occur when both the categories of forces and the different categories of modes are not jointly present too.
The hybrid nature and scope of EI

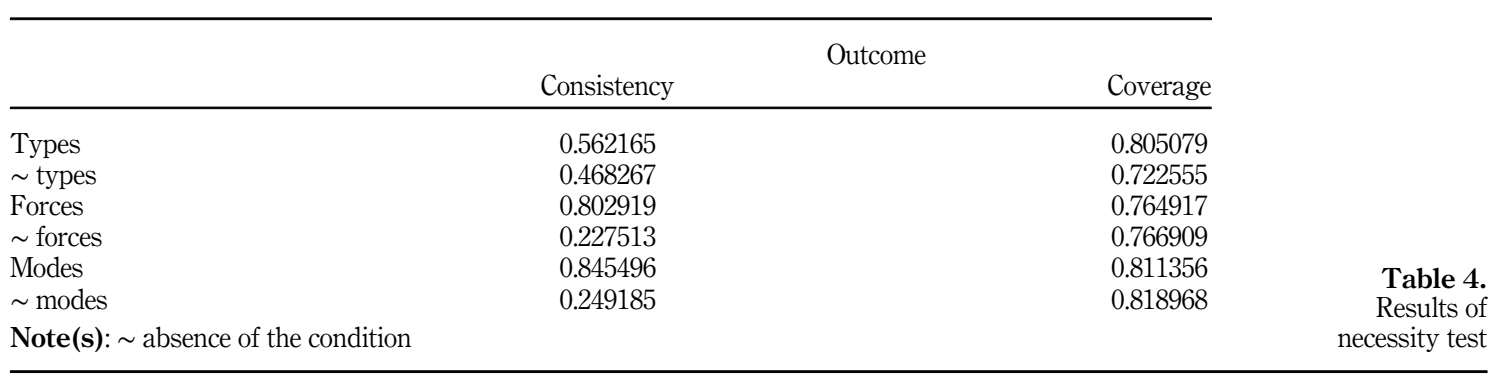


EJIM

24,4

\section{0}

In addition, the companies belonging to path 1 and path 3 report a wider range of both internal and external benefits. These include benefits related to energy savings and the reduction of the carbon footprint, the use of less polluting materials or the re-use of materials and water and the extension of the product life-cycle. Instead, the companies belonging to path 2 are mainly concentrated on internal and external benefits connected to energy rationalisation and the reduction of the carbon footprint.

Given the characteristics of the fsQCA, we were able to go back to the cases by identifying the typical cases and deepen our understanding of them (see Table 6).

Most of the typical cases are companies belonging to a corporate group. Many of the companies are large in terms of the number of employees, coherent with the structure of the sectors analysed. The vast majority of them count on qualified human resources and address international markets.

Additionally, the cases involved in path 1 mostly rely on external knowledge resources to address EI integrated benefits, and the investment in internal knowledge resources is often seen as conflicting and as leading to an either-on choice. In contrast, the companies in path 2 respond more to the business pressures in their EI strategy, leaving behind the possibility of innovation triggered by environmental rules and regulations.

\section{Conclusions}

This paper uses the paradox-based perspective to explore tensions that firms manage in order to achieve multiple EI benefits.

We move from the recent debate that addresses the reach of EI strategy from an integrative perspective; EI issues are believed to be the result of the long-term orientation to lower operating risks and input costs and to capture market opportunities for innovation and profitability (Adams et al., 2016; Watson et al., 2018). By adopting a more inclusive paradox view, we find it worthwhile to navigate the circumstances of the complexity and pluralism of EI benefits.

\begin{tabular}{lccc}
\hline Solution paths & Consistency & Coverage & Number of cases \\
\hline Solution path 1: types* $\sim$ modes & 0.877414 & 0.154088 & 10 \\
Solution path 2: types* forces & 0.892067 & 0.141489 & 10 \\
Solution path 3: forces* $\sim$ modes & 0.943452 & 0.0767478 & 3 \\
Note(s): $\sim$ absence of the condition & & & \\
$*$ logical AND & & & \\
\hline
\end{tabular}

Table 5.

Results of sufficiency test

\begin{tabular}{ll}
\hline & N. of companies \\
\hline Corporate group & Included : N.17 \\
Number of employees & Not included: N.4 \\
& Less than $50:$ N.6 \\
Employees with tertiary degree & $50-249:$ N.9 more than 250: N.6 \\
& Less than $50 \%$ of employees: N.3 \\
Selling market & More than $50 \%$ of employees: N.16 \\
& N.A.: N.2 \\
& Only regional and national market: N.4 \\
& International market: N.17
\end{tabular}

Table 6.

Descriptive statistics of Selling market typical cases 
More specifically, our research allows us to assess the relevance of conflicting aspects that are connatural to the complexity of EI. The extant literature has widely debated these aspects as leading elements of EI, but little is known about the variety and opposite dimensions they can assume and their subsequent effects on EI multidimensional benefits. In this study, we raise the questions of how the opposite elements of EI characteristics, including types, forces and modes of EI, can be arranged and combined to generate benefits for both the companies and the markets. Empirical evidence for the proposed relationships is provided by a dataset of European firms belonging to the telecommunication and ICT service sectors.

This paper makes original contributions to scientific and practice debates on EI, with implications for scholars, managers and policy makers.

\subsection{Theoretical implications}

First, this paper provides evidence of the multifaceted nature of EI benefits and their role in capturing the real nature of EI strategy. A considerable body of literature assumes that EI benefits, including cost reductions and market goals, as implicit aspects of general innovations that lower environmental impacts without any evidence of their interplay and multidimensional effects. Our results offer an integrated framework by coherently combining different EI benefits and including the analysis of the different EI conditions. In line with recent contributions on EI (Bonzanini-Bossle et al., 2016; Klewitz and Hansen, 2014; Hall et al., 2018), companies pay equal attention to internal resource reductions and externally generated benefits for customers, including a good image of environmental consciousness, in their practices of innovation. The identified need to combine internal and external benefits provides guidance for EI scholars on an integrative view that offers promising avenues for future research on a wide range of EI aspects.

Second, this paper explores EI tensions and thus explains how the abovementioned combinative effects of EI benefits can be achieved. The paper highlights that managing oppositional and combinative relationships between different EI conditions may disclose the potential of EI in terms of scope and benefits. The need to combine different EI benefits gives rise to multiple combinations of EI types, including process, product, organisational and market, suggesting that multiple aspects of innovation conditions can exist simultaneously. However, our results (solution path 2) show that integrated EI benefits are related to the determining role of business pressures as leading forces. In other words, business pressures produce integrated EI benefits when they manifest in articulated innovative efforts, i.e. of product and process types simultaneously. Frequently, the EI literature assumes that tensions accompany the relationship between normative and business pressures, and a theoretical integrative approach has identified instances where organisations are assumed to follow both (Testa et al., 2018; Yang et al., 2019); however, no evidence is produced to demonstrate that their EI fully reflects this. Our results suggest that there are differences between institutional and business pressures and that business interests still have prominent implications for ICT organisations. The research findings suggest that the business motives of environmental issues aid EI performativity; here, EI goals are set in the context of multiple product and process innovation tasks. In addition, as our results show (solution path 1), the impact on multiple companies' EI benefits also occurs when a mix of innovation types (product, processes, market and organisational) is combined with the search for external partners (Mothe and Nguyen-Ti, 2017). The role of ever-expanding external relationships is a central topic in the recent literature on open EI, with implications for internal resources (Ghisetti et al., 2015). Our results question the role of internal resources as companies still strive to balance in-house-generated knowledge and externally acquired technology for EI goals. This result can be attributed to the characteristics of ICT companies, which successfully collaborate with external partners without the need to strictly depend on their
The hybrid nature and scope of EI 
EJIM

24,4

in-house environmental technology-related capabilities (Rashidirad et al., 2018). The discussion of the three tensions offers promising avenues for systematic analysis of the EI phenomenon and provides a better understanding of its multifaceted and integrative nature. Environmental scholars could further identify and investigate additional tensions that firms face when dealing with environmental issues.

Third, our work provides an original contribution from the point of view of the conceptual and methodological paradox approach. The paradox-inspired approach has shown some usefulness in studies on sustainability, and it has mainly been addressed from a theoretical and abstract point of view. In contrast, our work takes the paradox-based approach to an empirical level by applying it to a much more specific area under the general sustainability domain of EI. The possibility of EI is sometimes interpreted as a dilemma that results in a trade-off between two or more opposing goals and tasks (Baumgartner, 2011). Assuming the possibility of multiple combinations between the two opposites, the paradox theory may support the development of a more holistic perspective of EI that claims a both-and rather than an either-or strategy. Furthermore, our empirical application has the merit of showing that fsQCA is a methodology particularly suitable for analysing the theme of EI under a paradox approach (Hahn et al., 2018). By allowing us to analyse constructs without having to reason in mutually exclusive terms, this methodology supports the understanding of how to grasp and measure the effects of the coexistence of different relevant conditions for EI even when they are the result of the interaction between apparently conflicting instances. As illustrated by the analysis, research on different tensions will require a different theoretical and methodological approach. It will be of interest for scholars to perform in-depth analysis of the characteristics of specific tensions by defining suitable conceptual and methodological paradox approaches for future research on EI. The interest could be to move beyond the simple analysis of each environmental dimension internal tensions to examine the complexity that arises when interrelated elements between different dimensions are considered simultaneously.

Finally, this work contains certain limitations that can mark the path for future EI research. The specific reference of our empirical analysis to the telecommunication and ICT sectors may be broadened by analysing other sectors or performing a cross-sectoral analysis. Additionally, some limitations are specifically connected to the CIS datasets from which the current analyses and findings originated. Some of these limitations have already been mentioned by other studies that have used it, and naturally, they are valid in our case as well (Ghisetti et al., 2015; Mothe and Nguyen-Ti, 2017); thus, further studies can extend and further the empirical datasets by analysing the empirical problem with additional data and elaborations.

\subsection{Managerial and policy implications}

The findings presented in this study also have important implications for managers and policymakers.

In managerial terms, our analysis can help companies better understand the mechanisms underlying their EI strategy and practices by identifying and mitigating the inherent conflicts and tensions. Recently, EI practitioners' interest has been in marketing the positive effect of environmental value. In particular, marketers have been advised to focus on communicating the relative advantage of EI over that of existing products and services. However, as argued in this study, focussing on only one side of benefits might be a myopic viewpoint. Managers must devote much more attention to the alignment between their EI decisions and overall strategy due to the emerging connections between the two. Managers who engage in complex environmental innovative efforts (product and process market) strive to generate direct benefits for their business as well as for end-users and the community. 
To achieve this result, however, they must also work on other aspects. Additionally, tensions need to be considered between the normative environment and competitive pressures, between internal investment and knowledge collaborations and sharing and between market and nonmarket forces. Doing so is an enormous challenge from a managerial perspective because it may require managers to overcome the short-term perspective in their strategic decision process.

Additionally, paradoxical resolution denotes purposeful iterations between alternatives to ensure simultaneous attention to them over time. A paradox logic can support managers in making the EI strategy more workable and reconciling the extremes as well as possible. However, moving beyond the tensions connected to some of them requires managers to consider different perspectives simultaneously. Paradox can serve as a mean for members of organisations to consider other viewpoints, alter their assumptions and explore issues in different ways. This may also suggest some interesting lines of future research connected to the individual characteristics that the managers who are able to adopt a paradox approach need to possess.

Moreover, our findings offer relevant indications for policymakers. Given that EI is a dynamic topic, policymakers encounter significant critical issues in managing the complexity associated with it (Basole et al., 2015). Indeed, policymakers need to become acquainted with these aspects. There is a need to stimulate and promote further decision-making mechanisms in companies that include environmental objectives within their business decisions and to enrich such objectives in terms of complexity. Gaining a better understanding of the connection between EI incentives and the business and strategic orientations of companies can help guide political orientation and policy measures by defining the right combinations of incentives and opportunities.

\section{References}

Adams, R., Jeanrenaud, S., Bessant, J., Denyer, D. and Overy, P. (2016), "Sustainability-oriented innovation: a systematic review", International Journal of Management Reviews, Vol. 18 No. 2, pp. 180-205.

Aguilera-Caracuel, J. and Ortiz-de-Mandojana, N. (2013), “Green innovation and financial performance: an institutional approach", Organization and Environment, Vol. 26 No. 4, pp. 365-385.

Albertini, E. (2013), "Does environmental management improve financial performance? A metaanalytical review", Organization and Environment, Vol. 26 No. 4, pp. 431-457.

Aragón-Correa, J.A. and Rubio-López, E.A. (2007), "Proactive corporate environmental strategies: myths and misunderstandings", Long Range Planning, Vol. 40, pp. 357-381.

Aschehoug, S.H., Boks, C. and Støren, S. (2012), "Environmental information from stakeholders supporting product development", Journal of Cleaner Production, Vol. 31, pp. 1-13.

Babiak, K. and Trendafilova, S. (2011), "CSR and environmental responsibility: motives and pressures to adopt green management practices", Corporate Social Responsibility and Environmental Management, Vol. 18 No. 1, pp. 11-24.

Basole, R.C., Park, H. and Barnett, B.C. (2015), "Coopetition and convergence in the ICT ecosystem", Telecommunications Policy, Vol. 39 No. 7, pp. 537-552.

Baumgartner, R.J. (2011), "Critical perspectives of sustainable development research and practice", Journal of Cleaner Production, Vol. 19 No. 8, pp. 783-786.

Belin, J., Horbach, J. and Oltra, V. (2011), Determinants and Specificities of Eco-Innovations - an Econometric Analysis for the French and German Industry Based on the Community Innovation Survey (No. 2011-17), Groupe de Recherche en Economie Théorique et Appliquée Bordeaux (GREThA).
The hybrid nature and scope of EI

1123 
EJIM

24,4

Berrone, P., Fosfuri, A., Gelabert, L. and Gomez-Mejia, L.R. (2013), "Necessity as the mother of 'green' inventions: institutional pressures and environmental innovations", Strategic Management Journal, Vol. 34 No. 8, pp. 891-909.

Blättel-Mink, B. (1998), "Innovation towards sustainable economy - the integration of economy and ecology in companies", Sustainable Development, Vol. 6 No. 2, pp. 49-58.

Bönte, W. and Dienes, C. (2013), "Environmental innovations and strategies for the development of new production technologies: empirical evidence from Europe", Business Strategy and the Environment, Vol. 22 No. 8, pp. 501-516.

Bonzanini-Bossle, M., de Barcellos, M.D., Vieira, L.M. and Sauvée, L. (2016), "The drivers for adoption of eco-innovation”, Journal of Cleaner Production, Vol. 113, pp. 861-872.

Buysse, K. and Verbeke, A. (2003), "Proactive environmental strategies: a stakeholder management perspective", Strategic Management Jorunal, Vol. 24, pp. 453-470.

Cainelli, G., Mazzanti, M. and Montresor, S. (2012), "Environmental innovations, local networks and internationalization", Industry and Innovation, Vol. 19 No. 8, pp. 697-734.

Camisón, C. (2010), "Effects of coercive regulation versus voluntary and cooperative auto-regulation on environmental adaptation and performance: empirical evidence in Spain”, European Management Journal, Vol. 28 No. 5, pp. 346-336.

Carrillo-Hermosilla, J., Rio, P. and Konnola, T. (2010), "Diversity of eco-innovations: reflections from selected case studies", Journal of Cleaner Production, Vol. 18 No. 10, pp. 1073-1083.

Chang, C.H. (2011), "The influence of corporate environmental ethics on competitive advantage: the mediation role of green innovation", Journal of Business Ethics, Vol. 104 No. 3, pp. 361-370.

Chen, Y.S., Chang, C.H. and Wu, F.S. (2012), "Origins of green innovations: the differences between proactive and reactive green innovations", Management Decision, Vol. 50 No. 3, pp. 368-398.

Cleff, T. and Rennings, K. (1999), "Determinants of environmental product and process innovation", European Environment, Vol. 9 No. 5, pp. 191-201.

Cooper, B. and Glaesser, J. (2016), "Qualitative comparative analysis, necessary conditions and limited diversity: some problematic consequences of Schneider and Wagemann's enhanced standard analysis", Field Methods, Vol. 28 No. 3, pp. 300-315.

Dangelico, R.M. (2016), "Green product innovation: where we are and where we are going”, Business Strategy and the Environment, Vol. 25 No. 8, pp. 560-576.

Dangelico, R. and Pujari, D. (2010), "Mainstreaming green product innovation: why and how companies integrate environmental sustainability", Journal of Business Ethics, Vol. 95 No. 3, pp. 471-486.

Darnall, N., Henriques, I. and Sadorsky, P. (2010), “Adopting proactive environmental strategy: the influence of stakeholders and firm size", Journal of Management Studies, Vol. 47 No. 6, pp. 1072-1094.

De Marchi, V. (2012), "Environmental innovation and R\&D cooperation: empirical evidence from Spanish manufacturing firms", Research Policy, Vol. 41, pp. 614-623.

De Marchi, V. and Grandinetti, R. (2013), "Knowledge strategies for environmental innovations: the case of Italian manufacturing firms", Journal of Knowledge Management, Vol. 17 No. 4, pp. 569-582.

De Medeiros, J.F., Ribeiro, J.L. and Cortimiglia, M.N. (2014), "Success factors for environmentally sustainable product innovation: a systematic literature review", Journal of Cleaner Production, Vol. 65, pp. 76-86.

del Río, P., Peñasco, C. and Romero-Jordán, D. (2016), "What drives eco-innovators? A critical review of the empirical literature based on econometric methods", Journal of Cleaner Production, Vol. 112, pp. 2158-2170. 
Di Paola, N. and Russo-Spena, T. (2019), "What drives biopharmaceutical firms' exploratory openness? A comparative process tracing approach to the analysis of R\&D microfoundations", Journal of Business Research, Vol. 97, pp. 94-103.

Díaz-García, C., González-Moreno, Á. and Sáez-Martínez, F.J. (2015), "Eco-innovation: insights from a literature review", Innovation, Vol. 17 No. 1, pp. 6-23.

Doran, J. and Ryan, G. (2016), "The importance of the diverse drivers and types of environmental innovation for firm performance", Business Strategy and the Environment, Vol. 25 No. 2, pp. 102-119.

Duşa, A. (2019), QCA with R A Comprehensive Resource, Springer, Cham.

Fiss, P.C. (2011), "Building better causal theories: a fuzzy set approach to typologies in organization research", Academy of Management Journal, Vol. 54 No. 2, pp. 393-420.

Franceschini, S. and Pansera, M. (2015), "Beyond unsustainable eco-innovation: the role of narratives in the evolution of the lighting sector", Technological Forecasting and Social Change, Vol. 92, pp. 69-83.

Galbreath, J. (2019), "Drivers of green innovations: the impact of export intensity, Women leaders and absorptive capacity", Journal of Business Ethics, Vol. 158 No. 1, pp. 47-61.

Ghisetti, C., Marzucchi, A. and Montresor, S. (2015), "The open eco-innovation mode. An empirical investigation of eleven European countries", Research Policy, Vol. 44 No. 5, pp. 1080-1093.

Gilli, M., Mancinelli, S. and Mazzanti, M. (2014), "Innovation complementarity and environmental productivity effects: reality or delusion? Evidence from the EU", Ecological Economics, Vol. 103, pp. 56-67.

Gonzalez-Padron, T.L. and Nason, R.W. (2009), "Market responsiveness to societal interests", Journal of Macromarketing, Vol. 29 No. 4, pp. 392-405.

Hahn, T., Preuss, L., Pinkse, J. and Figge, F. (2014), "Cognitive frames in corporate sustainability: managerial sensemaking with paradoxical and business case frames", Academy of Management Review, Vol. 39 No. 4, pp. 463-487.

Hahn, T., Figge, F., Pinkse, J. and Preuss, L. (2018), "A paradox perspective on corporate sustainability: descriptive, instrumental and normative aspects", Journal of Business Ethics, Vol. 148 No. 2, pp. 235-248.

Halila, F. and Rundquist, J. (2011), "The development and market success of eco-innovations: a comparative study of eco-innovations and "other" innovations in Sweden", European Journal of Innovation Management, Vol. 14 No. 3, pp. 278-302.

Hall, J., Matos, S., Gold, S. and Severino, L.S. (2018), "The paradox of sustainable innovation: the Eroom effect (Moore's law backwards)”, Journal of Cleaner Production, Vol. 172, pp. 3487-3497.

Heeks, R., Subramanian, L. and Jones, C. (2015), "Understanding e-waste management in developing countries: strategies, determinants, and policy implications in the Indian ICT sector", Information Technology for Development, Vol. 21 No. 4, pp. 653-667.

Hellstrom, T. (2007), "Dimensions of environmentally sustainable innovation: the structure of ecoinnovation concepts", Sustainability Development, Vol. 15 No. 3, p. $148 \mathrm{e} 159$.

Hojnik, J. and Ruzzier, M. (2016), "What drives eco-innovation? A review of an emerging literature", Environmental Innovation and Societal Transitions, Vol. 19, pp. 31-41.

Holm, J.R. and Østergaard, C.R. (2015), "Regional employment growth, shocks and regional industrial resilience: a quantitative analysis of the Danish ICT sector", Studies, Vol. 49 No. 1, pp. 95-112.

Hoogendoorn, B., Guerra, D. and van der Zwan, P. (2015), "What drives environmental practices of SMEs?", Small Business Economics, Vol. 44 No. 4, pp. 759-781.

Horbach, J., Rammer, C. and Rennings, K. (2012), "Determinants of eco-innovations by type of environmental impact - the role of regulatory push/pull. Technology push and market pull", Ecological Economics, Vol. 78, pp. 112-122.
The hybrid nature and scope of EI 
EJIM

24,4

Hu, D., Wang, Y. and Li, Y. (2017), "How does open innovation modify the relationship between environmental regulations and productivity?", Business Strategy and the Environment, Vol. 8 No. 26, pp. 1132-1143.

Huber, J. (2008), "Technological environmental innovations (TEIs) in a chain-analytical and life-cycleanalytical perspective", Journal of Cleaner Production, Vol. 16 No. 18, pp. 1980-1986.

Ivory, S.B. and Brooks, S.B. (2018), "Managing corporate sustainability with a paradoxical lens: lessons from strategic agility", Journal of Business Ethics, Vol. 148 No. 2, pp. 347-361.

Kan, A.K., Adegbite, E., El Omari, S. and Abdellatif, M. (2016), "On the use of qualitative comparative analysis in management”, Journal of Business Research, Vol. 69 No. 4, pp. 1458-1463.

Kennedy, S., Whiteman, G. and van den Ende, J. (2017), "Radical innovation for sustainability: the power of strategy and open innovation”, Long Range Planning, Vol. 50 No. 6, pp. 712-725.

Kesidou, E. and Demirel, P. (2012), "On the drivers of eco-innovations: empirical evidence from the UK”, Research Policy, Vol. 41 No. 5, pp. 862-870.

Ketata, I., Sofka, W. and Grimpe, C. (2015), "The role of internal capabilities and firms' environment for sustainable innovation: evidence for Germany", R\&D Management, Vol. 45, pp. 60-75.

Khosravi, P., Newton, C. and Rezvani, A. (2019), "Management innovation: a systematic review and meta-analysis of past decades of research", European Management Journal, Vol. 34, pp. 694-707.

Kiefer, C.P., Carrillo-Hermosilla, J., Del Río, P. and Barroso, F.J.C. (2017), "Diversity of eco-innovations: a quantitative approach", Journal of Cleaner Production, Vol. 166, pp. 1494-1506.

Kiefer, C.P., Del Río González, P. and Carrillo-Hermosilla, J. (2019), "Drivers and barriers of ecoinnovation types for sustainable transitions: a quantitative perspective", Business Strategy and the Environment, Vol. 28 No. 1, pp. 155-172.

Klewitz, J. and Hansen, E.G. (2014), "Sustainability-oriented innovation of SMEs: a systematic review", Journal of Cleaner Production, Vol. 65, pp. 57-75.

Kraus, S., Ribeiro-Soriano, D. and Schüssler, M. (2018), "Fuzzy-set qualitative comparative analysis ( $\mathrm{fSQCA}$ ) in entrepreneurship and innovation research-the rise of a method", The International Entrepreneurship and Management Journal, Vol. 14 No. 1, pp. 15-33.

Lee, J.J., Gemba, K. and Kodama, F. (2006), "Analyzing the innovation process for environmental performance improvement”, Technological Forecasting and Social Change, Vol. 73 No. 3, pp. 290-301.

Legewie, N. (2013), "An introduction to applied data analysis with qualitative comparative analysis", Forum Qualitative Sozialforschung/Forum: Qualitative Social Research, Vol. 14 No. 3, pp. 1-45.

Lewis, M.W. and Smith, W.K. (2014), "Paradox as a metatheoretical perspective: sharpening the focus and widening the scope", The Journal of Applied Behavioral Science, Vol. 50 No. 2, pp. 127-149.

Leyva-de la Hiz, D.I., Hurtado-Torres, N. and Bermúdez-Edo, M. (2019), "The heterogeneity of levels of green innovation by firms in international contexts: a study based on the home-country institutional profile", Organization and Environment, Vol. 32 No. 24, pp. 508-527.

Li-Ying, J., Mothe, C. and Nguyen, T.T.U. (2018), "Linking forms of inbound open innovation to a driver-based typology of environmental innovation: evidence from French manufacturing firms", Technological Forecasting and Social Change, Vol. 135, pp. 51-63.

Liao, Z. (2018), "Institutional pressure, knowledge acquisition and a firm's environmental innovation", Business Strategy and the Environment, Vol. 27 No. 27, pp. 849-857.

Livonen, K. (2017), "Defensive responses to strategic sustainability paradoxes-Have your coke and drink it too!", Journal of Business Ethics, Vol. 148, pp. 309-327.

Marin, G. and Lotti, F. (2017), "Productivity effects of eco-innovations using data on eco-patents", Industrial and Corporate Change, Vol. 26 No. 21, pp. 125-148. 
Mothe, C. and Nguyen-Thi, U.T. (2017), "Persistent openness and environmental innovation: an empirical analysis of French manufacturing firms", Journal of Cleaner Production, Vol. 162, pp. 59-69.

Murillo-Luna, J.L., Garcés-Ayerbe, C. and Rivera-Torres, P. (2011), "Barriers to the adoption of proactive environmental strategies", Journal of Cleaner Production, Vol. 19, pp. 1417-1425.

O'Driscoll, A. (2008), "Exploring paradox in marketing: managing ambiguity towards synthesis", Journal of Business and Industrial Marketing, Vol. 23 No. 22, pp. 95-104.

Porter, M.E. and Van der Linde, C. (1995), "Toward a new conception of the environmentcompetitiveness relationship", Journal of economic perspectives, Vol. 9 No. 24, pp. 97-118.

Pujari, D.. (2006), "Eco-innovation and new product development: understanding the influences on market performance", Technovation, Vol. 26 No. 21, pp. 76-85.

Ragin, C.C. (2000), Fuzzy-Set Social Science, University of Chicago Press, Chicago.

Ragin, C.C. (2008), Redesigning Social Inquiry: Fuzzy Sets and Beyond, Vol. 240, University of Chicago Press, Chicago.

Rashidirad, M., Salimian, H. and Soltani, E. (2018), "A contingency view to novelty: the role of productservice strategy, sensing capability and environmental turbulence", European Business Review, Vol. 30 No. 3, pp. 218-245.

Rauter, R., Perl-Vorbach, E. and Baumgartner, R.J. (2017), "Is open innovation supporting sustainable innovation? Findings based on a systematic, explorative analysis of existing literature", International Journal of Innovation and Sustainable Development, Vol. 11 Nos 2-3, pp. 249-270.

Rave, T., Goetzke, F. and Larch, M. (2011), The determinants of environmental innovations and patenting: Germany reconsidered (No. 97), Ifo Working Paper.

Rexhäuser, S. and Rammer, C. (2014), "Environmental innovations and firm profitability: unmasking the Porter hypothesis", Environmental and Resource Economics, Vol. 57 No. 1, pp. 145-167.

Sánchez-Medina, P.S., Díaz-Pichardo, R., Bautista-Cruz, A. and Toledo-López, A. (2015), "Environmental compliance and economic and environmental performance: evidence from handicrafts small businesses in Mexico", Journal of Business Ethics, Vol. 126 No. 3, pp. 381-393.

Schad, J., Lewis, M.W., Raisch, S. and Smith, W.K. (2016), "Paradox research in management science: looking back to move forward”, The Academy of Management Annals, Vol. 10 No. 1, pp. 5-64.

Schneider, C.Q. and Wagemann, C. (2012), Set-theoretic Methods for the Social Sciences: A Guide to Qualitative Comparative Analysis, Cambridge University Press, Cambridge.

Schiederig, T., Tietze, F. and Herstatt, C. (2012) "Green innovation in technology and innovation management - an exploratory literature review”, $R \&$ D Management, Vol. 42 No. 2, pp. 180-192.

Skaaning, S.E. (2011), "Assessing the robustness of crisp-set and fuzzy-set QCA results", Sociological Methods and Research, Vol. 40 No. 2, pp. 391-408.

Soderstrom, S.B. and Heinze, K.L. (2019), "From paradoxical thinking to practicing sustainable business: the role of a business collective organization in supporting entrepreneurs", Organization and Environment.

Stadtler, L. and Lin, H. (2019), "Leveraging partnerships for environmental change: the interplay between the partnership mechanism and the targeted stakeholder group", Journal of Business Ethics, Vol. 154 No. 3, pp. 869-891.

Testa, F., Boiral, O. and Iraldo, F. (2018), "Internalization of environmental practices and institutional complexity: can stakeholders pressures encourage greenwashing?", Journal of Business Ethics, Vol. 147 No. 2, pp. 287-307.

Triguero, A., Fernández, S. and Sáez-Martinez, F.J. (2018), "Inbound open innovative strategies and eco-innovation in the Spanish food and beverage industry", Sustainable Production and Consumption, Vol. 15, pp. 49-64. 
EJIM

24,4

\section{8}

Figure A1.

Membership function for the condition "modes of EI"
Wagner, M. (2009), "Innovation and competitive advantages from the integration of strategic aspects with social and environmental management in European firms", Business Strategy and the Environment, Vol. 18 No. 5, pp. 291-306.

Watson, R., Wilson, H.N., Smart, P. and Macdonald, E.K. (2018), "Harnessing difference: a capabilitybased framework for stakeholder engagement in environmental innovation", Journal of Product Innovation Management, Vol. 35 No. 2, pp. 254-279.

Xie, X., Huo, J. and Zou, H. (2019), "Green process innovation, green product innovation, and corporate financial performance: a content analysis method", Journal of Business Research, Vol. 101, pp. 697-706.

Yang, D., Wang, A.X., Zhou, K.Z. and Jiang, W. (2019), "Environmental strategy, institutional force, and innovation capability: a managerial cognition perspective", Journal of Business Ethics, Vol. 159 No. 4, pp. 1147-1161.

Yarahmadi, M. and Higgins, P.G. (2012), "Motivations towards environmental innovation: a conceptual framework for multiparty cooperation", European Journal of Innovation Management, Vol. 15 No. 4, pp. 400-420.

Yin, J., Gong, L. and Wang, S. (2018), "Large-scale assessment of global green innovation research trends from 1981 to 2016: a bibliometric study", Journal of Cleaner Production, Vol. 197, pp. 827-841.

Zeng, D., Hu, J. and Ouyang, T. (2017), "Managing innovation paradox in the sustainable innovation ecosystem: a case study of ambidextrous capability in a focal firm", Sustainability, Vol. 9 No. 11, pp. 1-15.

Zhao, Y., Feng, T. and Shi, H. (2018), "External involvement and green product innovation: the moderating role of environmental uncertainty", Business Strategy and the Environment, Vol. 27 No. 8, pp. 1167-1180.

\section{Appendix}

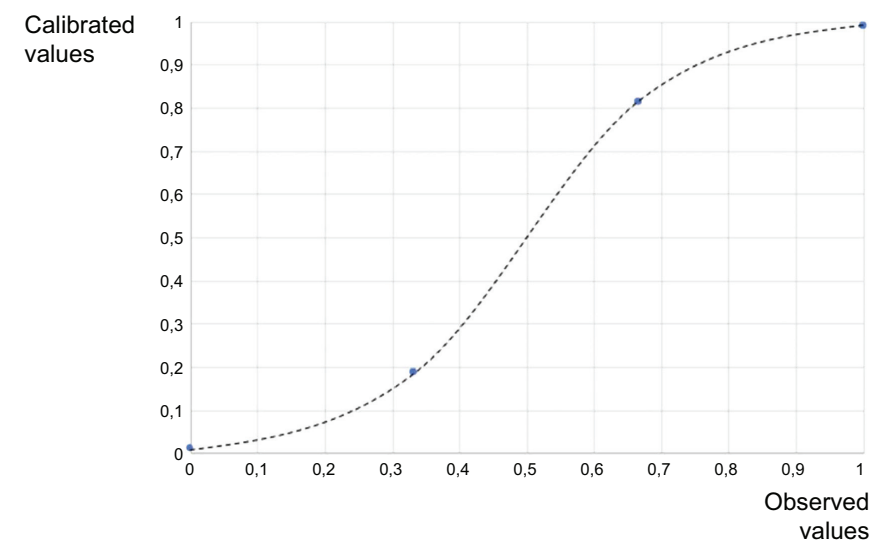

\section{About the authors}

Nadia Di Paola is an assistant professor of Business Management at the Department of Economics, Management and Institutions, University of Naples Federico II. Her main research interests cover the areas of innovation, entrepreneurship, startup management and technology venturing. She has written many articles and books. Her research has been published in a number of Italian and International Journals. 
Tiziana Russo Spena is an associate professor of Business Management at the Department of Economics, Management and Institutions, University of Naples Federico II. Her main areas of interest are innovation management, service innovation and marketing. She has written many articles and books and published in Italian and International Journals, including the Industrial Marketing and Management, Journal of Business Ethics, Journal of Service Theory and Practices, Journal of Service Management, Journal of Business Research. Tiziana Russo Spena is the corresponding author and can be contacted at: russospe@unina.it

The hybrid nature and scope of EI

For instructions on how to order reprints of this article, please visit our website: www.emeraldgrouppublishing.com/licensing/reprints.htm Or contact us for further details: permissions@emeraldinsight.com 